\title{
Avaliação da Atividade Citotóxica dos Extratos das Folhas de Erythroxylum Campestre (Erythroxylaceae) Frente às Células Sarcoma 180
}

Adriana G. Pereira, Antônio Carlos S. Menezes, Mirley L. dos Santos, Tamires S. Vieira, Renato G. Santos \& Elisângela P. S. Lacerda

O uso de plantas medicinais é descrito, desde os primórdios das civilizações, sendo ainda hoje uma importante fonte de recursos terapêuticos. A planta Erythroxylum campestre sp é pertencente ao gênero Erythroxylum. O interesse pelo gênero intensificouse no século XIX, após a descoberta das atividades farmacológicas apresentadas pelas folhas de Erythroxylum coca. A ocorrência desse gênero é descrita em ambientes florestais e de Cerrado sensu. Este trabalho tem por objetivo a avaliação da atividade citotóxica das frações (hexânica, diclorometânica, acetato de etila e metanólica) das folhas de Erythroxylum campestre frente a células tumorais do Sarcoma 180.

Palavras-chave: Atividade Citotóxica; Erythroxylum campestre sp; Sarcoma 180.

The use of medicinal plant has been described since civilizations' first living, and it is still an important source of therapeutic resources nowadays. The plant Erythroxylum campestre sp belongs to the genus Erythroxylum. Interest in the genus has been intensified since the XIX century, after the discovery of pharmacological activities presented by the leaves of Erythroxylum coca. The occurrence of this genus is described in forest environments and sensu Cerrado (Savanna). This work aims at evaluating the cytotoxic activity of fractions (hexane, dichloromethane, ethyl acetate and methanol) from the leaves of Erythroxylum campestre sp regarding tumor cells of Sarcoma 180.

Keywords: Cytotoxic activity; Erythroxylum campestre sp; Sarcoma 180. 


\section{Introdução}

O ser humano sempre buscou na natureza soluções para seus males ${ }^{1}$. Dentre essas, destaca-se o uso de substâncias orgânicas provenientes de fontes naturais, como, por exemplo, de plantas, as quais têm representado para o ser humano, durante anos, a principal forma de recurso terapêutico ${ }^{2}$. Tal inferência é reforçada pelo fato de que o uso dessas para o tratamento de inúmeras doenças é descrito por várias civilizações de mais de cinco mil anos, tais como as de origem chinesa, indiana e africana ${ }^{3}$.

Não obstante, no que diz respeito aos dias atuais, ressalta-se que, em média, $25 \%$ dos medicamentos prescritos em todo o mundo são obtidos direta ou indiretamente a partir de plantas. Com o intuito de enfatizar a importância do estudo de plantas, faz-se necessário mencionar que apenas entre os anos de 1981 a 2002, compostos provenientes de produtos naturais, análogos semissintéticos ou ainda compostos sintéticos baseados nos mesmos foram responsáveis por aproximadamente $49 \%$ de todas as drogas desenvolvidas ${ }^{4}$.

Em relação à importância das substâncias provenientes de plantas, como exemplo prático, destacam-se descoberta e aplicação da substância forscolina, extraída de Coleus barbatus, com vistas ao tratamento de várias doenças, tais como hipertensão, glaucoma, asma e alguns tipos de tumores ${ }^{5}$.

No que se refere aos tumores, popularmente conhecidos como câncer, cientificamente denominado pelo termo neoplasia, principalmente no que tange aos tumores malignos, trata-se de uma doença caracterizada pelo crescimento descontrolado de células doentes. $\mathrm{O}$ índice de mortalidade dessa doença tem sido considerado bastante alto, devido, primordialmente, à quantidade de tipos, cerca de 200, associado ao ataque de vários órgãos do corpo, além das dificuldades encontradas em seu tratamento, tais como complicações associadas à resistência ao medicamento, toxicidade e baixa especificidade ${ }^{6,7}$.

No que concerne ao tratamento do câncer, vários outros estudos foram e têm sido desenvolvidos a partir de produtos naturais. Dentre as descobertas nesse ramo, destaca-se, o taxol, um isolado das cascas do Taxus brevifolia, especificamente um diterpeno, que, por sua vez, tem sido amplamente utilizado no tratamento de vários tipos de câncer, como de ovários e pulmões ${ }^{8,9,10}$.

Nesse ínterim, ressalta-se que a busca de novos medicamentos para o tratamento do câncer é de suma importância para a sociedade como um todo, devido ao fato da estimativa de que até 2020 , o número de novos casos anuais em todo o mundo seja da ordem milhões, dos quais $60 \%$ ocorrerão em países em desenvolvimento ${ }^{11}$.

Dada a devida importância supracitada às plantas, principalmente no tocante ao combate ao câncer, fazse imprescindível que o Brasil, como um todo, por ser um dos países mais ricos em biodiversidade, faça uso apropriado dessa biodiversidade, principalmente, a vegetal, e invista cada vez mais em seu estudo fitoquímico e consequentemente farmacológico, o que, muitas vezes, não ocorre ${ }^{12}$.

A família Erythroxylaceae Kunth é uma das mais representativas dos cerrados ${ }^{13}$. O gênero Erythroxylum é formado por cerca de 250 espécies $^{14}$, distribuídas nas regiões tropicais e subtropicais do mundo, sendo que, para o Brasil, é descrita a ocorrência de aproximadamente 130 espécies, em ambientes florestais e de Cerrado latu censu ${ }^{15}$. Várias espécies do gênero possuem propriedades medicinais, sendo as populares cocas (E. coca Lamk. e E. novogranatense (D.Morris Hieron.) e suas variedades as mais conhecidas e estudadas, devido à presença de alcaloides em suas folhas ${ }^{16}$.

Além disso, das espécies do gênero Erythroxylum que se tem registrado na literatura científica, apenas 63 foram estudadas, o que evidencia que o gênero tem sido pouco investigado ${ }^{17}$.

$\mathrm{O}$ interesse pelo gênero intensificou-se no século XIX, após a descoberta das atividades farmacológicas apresentadas pelas folhas de Erythroxylum coca ${ }^{14}$, que produzem um alcaloide natural, a cocaína, muito utilizada como anestésico local em pequenas cirurgias ${ }^{18,19}$.

Devido à atividade biológica de Erythroxylum campestre, empiricamente conhecida como fruta-tucano, cabelo-de-negro ou coco do Paraguai, esta tem sido amplamente utilizada para diversos fins terapêuticos na medicina popular ${ }^{20}$. Dentre suas aplicações, cita-se como exemplo seu uso na forma de infuso como laxante ${ }^{21,22}$.

Em face dessas considerações, o objetivo do presente estudo foi avaliar a atividade citotóxica em células de sarcoma 180 (S180) de diferentes frações obtidas das folhas de Erythroxylum campestre (Erythroxylaceae). 


\section{Materiais e Métodos}

\section{MATERIAL VEGETAL}

A parte do vegetal estudada foram as folhas. A coleta do material foi feita no Campus Henrique Santillo da Universidade Estadual de Goiás, em Anápolis, GO. A identificação da planta foi feita pela Prof ${ }^{a}$. Dra. Mirley Luciene dos Santos e sua exsicata $\left(n^{\circ} 10294\right)$ foi armazenada no herbário do departamento de Ciências Biológicas da UEG. Após a coleta, o material foi selecionado e submetido à secagem em estufa ventilada a $40{ }^{\circ} \mathrm{C}$ (MA035 - Marconi).

Após a secagem, o material vegetal foi pulverizado em moinho de facas (tipo cróton Modelo MA-580), foi pesado e colocado em contato com o solvente metanólico para que se iniciasse o processo de extração exaustiva dos constituintes. Em seguida, o filtrado resultante da extração foi recolhido e o solvente orgânico evaporado em evaporador rotativo à vácuo (TECNAL-120) em uma temperatura de aproximadamente $40^{\circ} \mathrm{C}$ fornecendo, portanto, o extrato bruto metanólico.

\section{PARTIÇÃO LÍQUIDO-LÍQUIDO DO EXTRATO BRUTO}

Após a evaporação do solvente, o extrato bruto metanólico das folhas (ECFM) de Erythroxylum campestre foi solubilizado em metanol e água (1:3), a fim de que todos os constituintes se solubilizassem por completo. Em seguida, o extrato metanólico foi fracionado por partição líquido-líquido. Sendo os solventes utilizados por ordem crescente de polaridade, a citar: hexano, diclorometano e acetato de etila. Obtendo-se, assim, as frações hexânica (ECFM-H), diclorometânica (ECFM-D) e acetato de etila (ECFM-A), conforme elucidado na Figura 1.

Para a preparação do extrato hexânico (apolar), transferiu-se a solução constituída do extrato bruto, metanol e água (1:3) para um funil de separação, no qual foi adicionado hexano, obtendo-se, assim, duas fases, separadas por polaridade, além da formação de um precipitado, denominado ECFM-ppt $(58,73 \mathrm{~g})$, sendo este separado da fase aquosa por filtração a vácuo.

Ressalta-se que o mesmo procedimento foi realizado para os demais solventes, diclorometano e acetato de etila. Sendo que, ao término dos procedimentos supracitados, todas as soluções obtidas foram submetidas

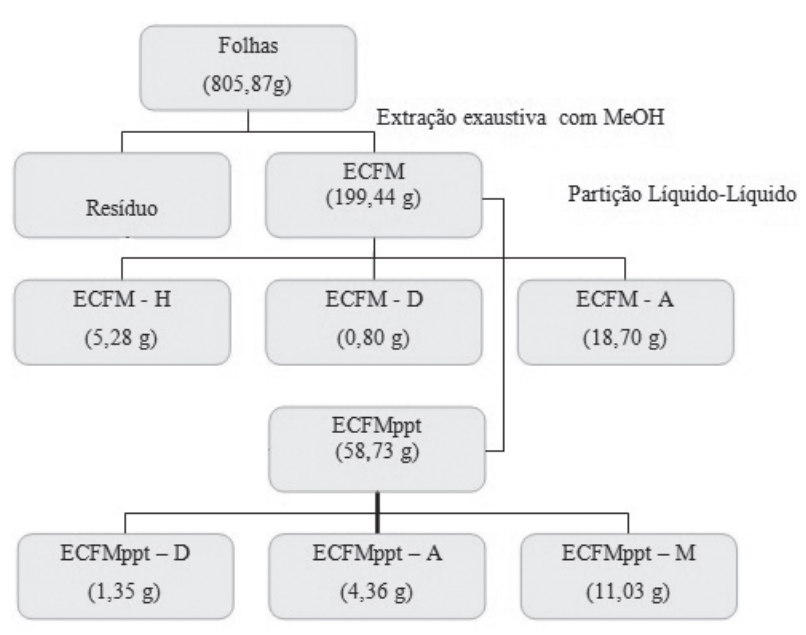

Figura 1. Obtenção das frações a partir das folhas da Erythroxylum campestre.

à rotoevaporação recuperando-se os solventes e obtendose seus respectivos extratos fracionados.

No que concerne ao precipitado obtido da solução aquosa metanólica. Este, por sua vez, foi submetido ao fracionamento por cromatografia em coluna aberta $(\varphi=$ $3 \mathrm{~cm} \mathrm{x} \mathrm{h}=20 \mathrm{~cm}$ ) utilizando-se celulose microcristalina $\mathrm{D}$ como fase estacionária e eluentes em ordem crescente de polaridade: diclorometano, acetato de etila e metanol, obtendo-se, dessa forma, as frações: diclorometânica (ECFMppt-D), acetato de etila (ECFMppt-A) e metanólica (ECFMppt-M), conforme mostrado na Figura 1.

\section{TESTE PARA ALCALOIDES}

O teste para verificação da presença de alcaloides nas frações obtidas das folhas da Erythroxylum campestre foi realizado por meio de cromatografia em camada delgada - CCD, utilizando-se cromatofolhas de alumínio como suporte e sílica gel 60 F254 como adsorvente. Como fase móvel, utilizou-se diclorometano / metanol 5\% e o reagente Dragendorff como revelador.

\section{PREPARAÇÃO DAS FRAÇÕES VEGETAIS E FÁRMACO CONTROLE PARA TESTE DE ATIVIDADE CITOTÓXICA IN VITRO}

Para a avaliação da atividade citotóxica in vitro selecionaram-se as frações hexânica (ECFM-H) e acetato de etila (ECFM-A), bem como as frações provenientes 
do precipitado (ECFMppt), sendo estas, diclorometânica (ECFMppt-D), metanólica (ECFMppt-M) e acetato de etila (ECFMppt-A). Entretanto, destaca-se que a fração diclorometânica (ECFM-D) não foi submetida a testes, devido ao seu baixo rendimento $(0,8 \mathrm{~g})$. Dessa forma, para cada teste, foram pesados $10 \mathrm{mg}$ de cada extrato, os quais foram solubilizados em $2 \mathrm{~mL}$ de meio de cultura RPMI nas concentrações de $0,001 \mathrm{mg} \cdot \mathrm{mL}^{-1}$, 0,01 mg.mL $\mathrm{mL}^{-1}, 0,1 \mathrm{mg} \cdot \mathrm{mL}^{-1}$ e $1 \mathrm{mg} \cdot \mathrm{mL}^{-1}$. Como controle positivo, foi utilizado o fármaco cisplatina.

\section{CÉLULAS DO S180}

Utilizou-se a linhagem tumoral primária do S180, obtida da Coleção Americana de Cultura de Células (ATCC, American Type Culture Collection). As linhagens tumorais do S180 foram cedidas pelo Laboratório de Umunologia da Universidade Federal de Uberlândia ao Laboratório de Genética Molecular e Citogenética da Universidade Federal de Goiás, onde foram realizados os testes.

\section{ENSAIO DA CITOTOXICIDADE}

A atividade citotóxica das frações de Erythroxylum campestre foi avaliada pelo método colorimétrico MTT [3-(4,5-Dimetiltiazol-2-il)2,5-Difenil Brometo de Tetrazolium $]^{23}$, conforme descrito a seguir.

Este ensaio baseia-se na medida do dano induzido pela droga no metabolismo celular pela atividade enzimática mitocondrial das células vivas. Quando as células estão vivas, as desidrogenases mitocondriais são capazes de agir sobre substratos como o MTT levando à quebra desta molécula e à redução dela, formando, assim ,o azul de formazan. Portanto, quanto maior a viabilidade celular em determinada amostra, mais azul de formazan é formado.

O azul de formazan é, então, solubilizado com dodecil sulfato de sódio (SDS) em meio ácido. Já a quantificação da inibição enzimática é realizada espectrofotometricamente, permitindo a obtenção dos valores de $\mathrm{IC}_{50}$ (concentração das drogas que inibem 50\% da atividade enzimática).

Para o teste de citotoxidade, as células do S180 foram plaqueadas na quantidade de $1 \times 10^{5}$, em triplicata, na microplaca de 96 poços, e incubadas por 24 e 48 horas em estufa a $37^{\circ} \mathrm{C}$ contendo $95 \%$ de ar e $5 \%$ $\mathrm{CO}_{2}$. O tratamento foi feito com as frações (ECFM-H, ECFM-A, ECFMppt-A, ECFMppt-D e ECFMppt-M) nas concentrações de $0,001 \mathrm{mg} \cdot \mathrm{mL}^{-1}, 0,01 \mathrm{mg} \cdot \mathrm{mL}^{-1}, 0,1$ mg.mL $\mathrm{mL}^{-1}$ e $1 \mathrm{mg} \cdot \mathrm{mL}^{-1}$.

Após a incubação de 24 e 48 horas, foram adicionados aos poços de cultivo celular utilizada, $10 \mu \mathrm{L}$ de MTT na concentração de $5 \mathrm{mg} \cdot \mathrm{mL}^{-1}$. A placa foi novamente incubada em estufa a $37^{\circ} \mathrm{C}$ contendo $95 \%$ de ar e $5 \% \mathrm{CO}_{2}$ e após 3 horas foram adicionados aos poços de cultivo celular $50 \mu \mathrm{L}$ de solução a $10 \%$ de SDS/ HCl 0,01 mol.L-1 para dissolver os sais de formazan formados.

A quantificação da densidade óptica foi medida após 24h do tratamento com SDS, em espectrofotômetro (Leitor para Elisa) utilizando-se filtro de interferência de $550 \mathrm{~nm}$.

\section{Análise Estatística}

A verificação das diferenças significativas entre os grupos estudados foram aplicados por meio de softwares (GraphPad Prismain ou SPSS) e pela análise de variância (ANOVA).

A variabilidade ou dispersão dos dados obtidos para um determinado parâmetro foi medida através da faixa de variação ou range (diferença entre o valor máximo e o valor mínimo), desvio-padrão da média e variância. Sendo considerado como diferença estatística significativa valor de $\mathrm{p}$ menores que $0,05(\mathrm{p}<0,05)$.

Para o cálculo da IC50, foram utilizados os dados dose-resposta (x: concentrações da droga; y: inibição de crescimento), cujos valores de y foram de a 0-1. Frequentemente, a regressão linear não é um bom ajuste aos dados de dose-resposta. A resposta da curva se ajusta melhor a uma linha reta, se o eixo x é o logaritmo transformado. Esta é uma função padrão na maioria dos softwares estatísticos.

\section{Resultados}

\section{TRATAMENTOS DE 24 HORAS}

Considerando-se valores significativos percentuais acima de $30 \%$, os dados obtidos mostraram que a fração de acetato de etila de Erythroxylum campestre (ECFMppt-A) testada por 24 horas não apresentou citotoxicidade significativa para as concentrações de 0,01 $\mathrm{mg} \cdot \mathrm{mL}^{-1}$ e $0,1 \mathrm{mg} \cdot \mathrm{mL}^{-1}$. Já em relação à concentração de $1 \mathrm{mg} \cdot \mathrm{mL}^{-1}$ a citotoxicidade foi de $49,72 \%$, conforme observado na Figura 2. 


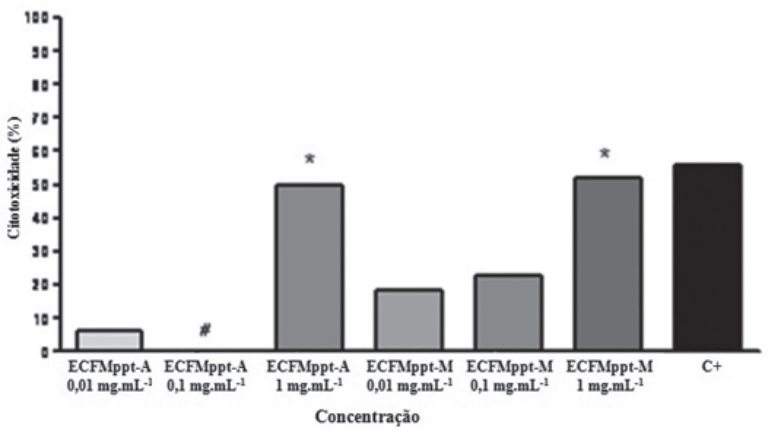

Figura 2. Atividade citotóxica da fração de acetato de etila (ECFMppt-A) e metanólica (ECFMppt-M) da folha de Erythroxylum campestre frente à linhagem tumoral S180 após 24 horas. $\mathrm{C}+=$ cisplatina $\left(0,05 \mathrm{mg} \mathrm{mL}^{-1}\right)$.

Em contrapartida, a fração metanólica de Erythroxylum campestre (ECFMppt-M) apresentou citotoxicidade significativa frente à linhagem de células estudadas. Os resultados mostraram um percentual de citotoxicidade de $52,21 \%$ para a concentração de $1 \mathrm{mg} \cdot \mathrm{mL}^{-1}$ e de $18,18 \%$ para a concentração de $0,01 \mathrm{mg} \cdot \mathrm{mL}^{-1}$.

Nesse sentido, infere-se, a partir das discussões dos dados obtidos, que ambas as frações com concentração de 1 mg.mL $\mathrm{m}^{-1}$ demonstram-se bastante promissoras, haja vista que apresentam citotoxicidade semelhante ao fármaco controle.

\section{TRATAMENTOS DE 48 HORAS}

Analisando-se os dados ilustrados na Figura 3, verificou-se que entre as frações testadas por 48 horas, a fração ECFMppt-Aapresentou uma viabilidade de 56,51\% para a maior concentração testada $\left(1 \mathrm{mg} \cdot \mathrm{mL}^{-1}\right)$. Contudo, tal citotoxicidade mostrou ser dose-dependente, visto que a diminuição da concentração do extrato acarretou em um aumento da viabilidade celular, sendo esta maior que o próprio controle negativo. Resultado estatisticamente significativo $(p=0,0012)$, apresentando IC50 de 0,301 $\mathrm{mg} \cdot \mathrm{mL}^{-1}$. Ainda, observa-se que a menor concentração testada $\left(0,001 \mathrm{mg} \cdot \mathrm{mL}^{-1}\right)$ apresentou viabilidade de $118,9 \%$, ou seja, evidenciando proliferação celular.

No que concerne à análise dos dados, da fração ECFMppt-M em tratamento por 48 horas, apresentados

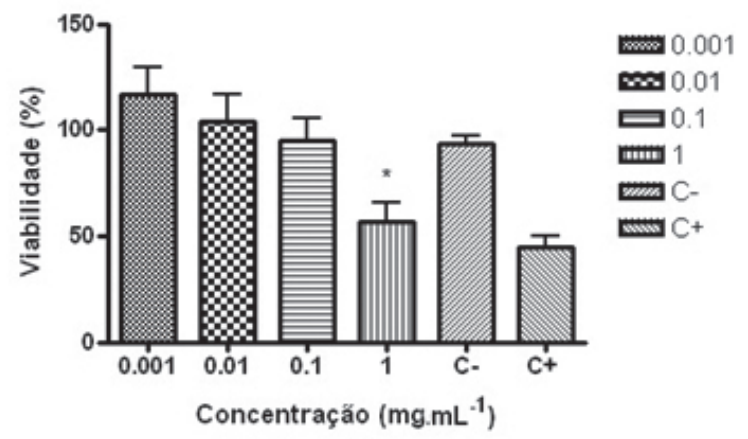

Figura 3. Percentual de Viabilidade Celular da fração de Acetato de Etila (ECFMppt-A) das folhas de Erythroxylum campestre frente à linhagem tumoral S180 após 48 horas.

na Figura 4, observou-se que houve viabilidade celular de $50,84 \%$ para a concentração de $1 \mathrm{mg} \cdot \mathrm{mL}^{-1}$ $(\mathrm{p}=0,0003)$, representando um resultado significativo quando comparado ao controle positivo, uma vez que seu percentual de inibição é equivalente ao mesmo.

Analisando-se os dados expostos na Figura 5 para a fração ECFMppt-D, verificou-se que esta apresentou viabilidade de $70,73 \%$ para a concentração de $1 \mathrm{mg} \cdot \mathrm{mL}^{-1}$. Entretanto, para as concentrações 0,01 e $0,001 \mathrm{mg} \cdot \mathrm{mL}^{-1}$ notou-se o surgimento de proliferação celular, o que remete a um resultado não significativo, $(\mathrm{p}<0,05)$.

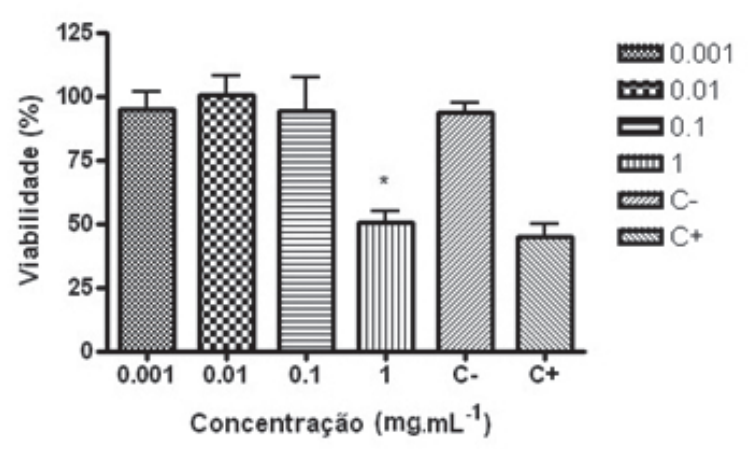

Figura 4. Percentual de Viabilidade Celular da fração ECFMppt-M das folhas de Erythroxylum campestre frente à linhagem tumoral S180 após 48 horas. 


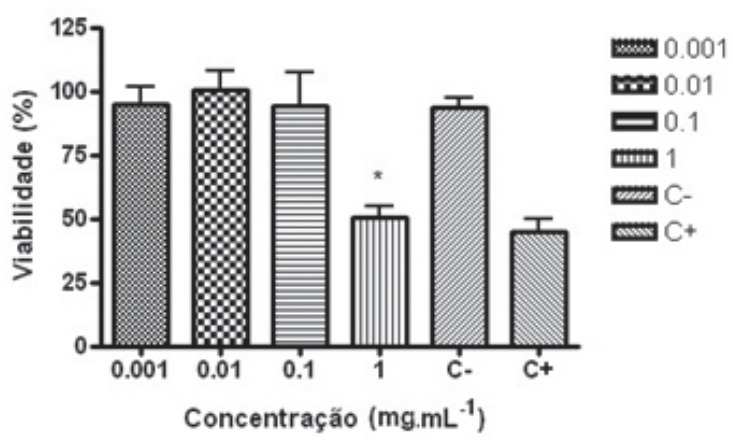

Figura 5. Percentual de Viabilidade Celular da fração ECFMppt-D das folhas de Erythroxylum campestre frente à linhagem tumoral S180 após 48 horas.

Em relação ao tratamento com a fração hexânica (ECFM-H), ao explorar os dados apresentados na Figura 6 , observa-se que esta não mostrou atividade citotóxica para as concentrações testadas, apresentando $85,8 \%$ de viabilidade para a concentração de $1 \mathrm{mg} \cdot \mathrm{mL}^{-1}(\mathrm{p}<0,05)$. Resultados análogos são encontrados para as demais concentrações.

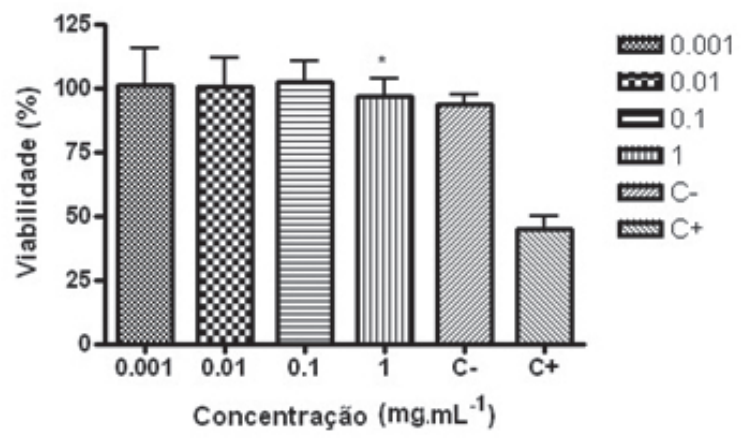

Figura 6. Percentual de Viabilidade Celular da fração ECFM-H das folhas de Erythroxylum campestre frente à linhagem tumoral S180 após 48 horas.

Por sua vez, a fração de acetato de etila (ECFM-A), conforme representada na Figura 7, demonstrou uma citotoxicidade mais representativa em comparação aos demais extratos na menor concentração testada $\left(0,001 \mathrm{mg} \cdot \mathrm{mL}^{-1}\right)(\mathrm{p}<0,05)$. No entanto, ao aumentar a concentração do extrato, a viabilidade também se elevou, o que pode ser justificado pelo fato das células terem metabolizado o excesso do extrato ao perceberem sua elevada citotoxicidade, apresentando, assim, resistência. Ainda, faz-se imprescindível salientar que tais extratos apresentaram efeitos inibitórios melhores que o próprio fármaco controle.

Ademais, salienta-se que a análise dos dados supracitados também pode ser inferida a partir do estudo da Figura 8, que versa sobre a concentração inibitória dos extratos estudados. Assim como da Tabela 1, a partir da elucidação dos valores de IC50. Analisando a citotoxicidade das frações in vitro frente ao modelo experimental utilizado, obtivemos os melhores resultados para as frações ECFMppt-A, ECFMppt-M e ECFM-A.

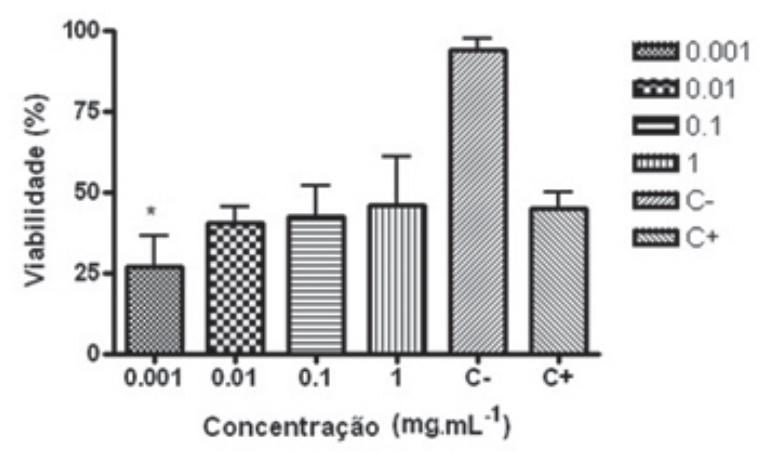

Figura 7. Percentual de Viabilidade Celular da fração de ECFM-A da folha de Erythroxylum campestre frente à linhagem tumoral S180 após 48 horas.

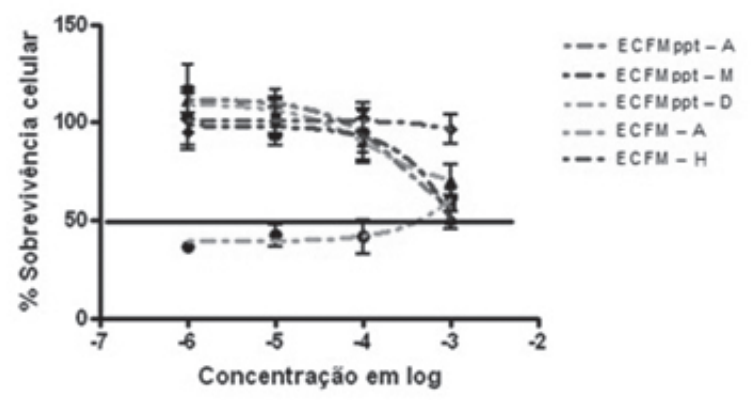

Figura 8. Curvas da IC50 dos testes de $48 \mathrm{~h}$ 
Tabela 1. Atividade de citotoxicidade in vitro de extratos da folha de Erythroxylum campestre em célula tumoral S180, determinada pelo teste de MTT após 48 horas de exposição. Os valores de IC50 expressão a média das triplicas e o desvio padrão.

\begin{tabular}{|c|c|c|}
\hline EXTRATO BRUTO & IC50 & SD \\
\hline ECFMppt - A & $0.30 \mathrm{mg} \cdot \mathrm{mL}^{-1}$ & \pm 0.2 \\
\hline ECFMppt - D & $6.20 \mathrm{mg} \cdot \mathrm{mL}^{-1}$ & \pm 0.2 \\
\hline ECFMppt - M & $0.11 \mathrm{mg} \cdot \mathrm{mL}^{-1}$ & \pm 0.2 \\
\hline ECFM - A & $3.84 \mathrm{mg} \cdot \mathrm{mL}^{-1}$ & \pm 0.3 \\
\hline ECFM - H & $47.68 \mathrm{mg} \cdot \mathrm{mL}^{-1}$ & \pm 0.3 \\
\hline
\end{tabular}

Um dos responsáveis por apresentar propriedades anticarcinogênica de grande importância farmacológica são os alcaloides, e estes foram identificados por meio do teste com o agente revelador Dragendorff nas frações do extrato de acetato de etila. Assim sendo, pode-se inferir que o alto percentual de citotoxicidade observado por esse extrato é decorrente da presença destes metabólitos.

É evidente que o gênero Erythroxylum é detentor de um grande potencial citotóxico quando comparado a outros gêneros e, portanto, faz-se necessária uma avaliação mais ampla e detalhada de seus constituintes químicos por meio de ensaios biomonitorados, visando à busca de princípios ativos para o desenvolvimento de novos fármacos com potencialidade citotóxica frente a células tumorais.

\section{Conclusão}

Com base nos resultados supracitados, conclui-se que as frações das folhas de Erythroxylum campestre testadas, por meio do método de MTT, apresentam citotoxicidade variável (entre 3,96\% e 56,51\%) sobre as células de Sarcoma 180. Ademais, por meio das análises estatísticas, notou-se que a fração de Acetato de Etila apresentou maior citotoxicidade, com $\mathrm{IC}_{50}$ de 0,301 nos testes de $48 \mathrm{~h}$, enquanto as demais frações apresentaram IC $50>1$. No que diz respeito à fração hexânica, não se observou atividade antitumoral significante frente a células do S180. Ainda, evidenciou-se que as frações de acetato de etila apresentaram resultado positivo para o teste de alcaloides.

\section{Referências}

1. Carvalho, J. E., Atividade Antiulcerogênica e Anticâncer de Produtos Naturais e de Síntese, Divisão de Farmacologia e Toxicologia. Unicamp, 07-out, 2006.

2. Hostettmann, K; queiroz, E.F; vieira, P.C. Princípios Ativos de Plantas Superiores. Série de textos da escola de Verão em Química. São Carlos. Edufscar. vol. IV, 2003.

3. Zhang, JT. New Drugs Derived from Medicinal Plants. Therapie, v. 57, p. 137-150, 2002.

4. Koehn, F. E.; carter, G.T. The evolving role of natural products in drug discovery. Nat. Rev. Drug Discovery, v. 4, n. 3, p. 206-220, 2005.

5. De Souza, N. J. Industrial development of traditional drugs: the forskolin example. A mini-review. J. Ethnopharmacol. v.38, p.177-180, 1993

6. Almeida, V. L. et al. Câncer e agentes antineoplásicos ciclocelular específicos e ciclo celular não específico que interagem com o DNA: uma introdução. Quím. Nova, v. 28, n.1, p. 118-129, 2005.

7. Mesquita, M. L. ; De Paula, J. E.; Pessoa, C.; De Moraes, M. O.; Costa-Lotufo, L. V.; Grougnet, R.; Michel, S.; Tillequin, F.; Espindola, L. S. Cytotoxic activity of Brazilian Cerrado plants used in traditional medicine against cancer cell lines. J. Ethnopharmacol. v. 123, p. 439-445, 2009.

8. Kingston, D. G. I. The chemistry of taxol. Pharmacology \& Therapeutics. v.52, p.1-34, 1991.

9. Horwitz, D. G. I. How to make taxol from scratch. Nature. 367, p. 593-594, 1994.

10. Corrêa, A. G. Taxol: da Descoberta ao Uso Terapêutico. Quím. Nova, v. 18, n. 5, p. 460-467, 1995.

11. Instituto Nacional do Câncer (INCA). http://www2.inca.gov.br/ $\mathrm{wps} / \mathrm{wcm} /$ connect/inca/portal/home, acessado em 30/04/2010.

12. Pinto, A. C. ; Silva, D. H. S. ; Bolzani, V. S. ; Lopes, N. P. ; Epifânio, R. A.. Produtos Naturais: Atualidade, Desafios e Perspectivas. Quím. Nova, São Paulo, v. 25, n.supl1, p. 1, 2002.

13. Nakamura, A. T. Morfologia e anatomia dos frutos e sementes de três espécies de Erythroxylum P. Browne (Erythroxylaceae). Biota Neotropica [online], 2005, vol.5, n.1, pp. 205-206

14. Zuanazzi et al. Alkaloids of Erythroxylum (Erythroxylaceae) species from Southern Brazil. Biochem. Syst. Ecol. 29: 819-825, 2001.

15. Amaral Junior, A. Erythroxilaceae. In Flora ilustrada catarinense (R. Reitz, ed.). Herbário Barbosa Rodrigues, Itajaí, p. $64,1980$.

16. Bieras, A. C.; Sajo, M. D. G. Foliar ontogeny of three species of Erythroxylum P. Browne (Erythroxylaceae) from Cerrado. Rev. Bras. Bot. v. 27, n. 1, p. 71-77, 2004. 
17. Garcia, K. G., Lavaut, J. A. G., Guevara, J. G., González, S. P. Género Erythroxylum: Análisis de la Información Científica. Acta Farm. Bonaerense, 24 (2): 284-90, 2005.

18. Bohm, B. A.; Ganders, F. R. \& Plowman, T. Biosystematics and evolution of cultivated coca (Erythroxylaceae). Syst. Bot. p. 121$133,1982$.

19. Griffin, W.J. \& Lin, G.D. Chemotaxonomy and geographical distribution of tropane alkaloids. Phytochemistry, 53: 627-628, 2000.

20. Barbosa, A. V. G. et al. Flora dos Estados de Goiás e Tocantins: Erythroxylaceae. Goiânia: Editora UFG, p. 23-73, 2001.

21. Rodrigues, V. E. G.; Carvalho, D. A. Levantamento etnobotânico de plantas medicinais no domínio do cerrado do Alto Rio GrandeMinas Gerais. Ciências Agrotécnicas, Lavras, v.25, n.1, p. 102123, jan./fev., 2001.

22. Colodel, E. M. et al. Intoxicação por Erythroxylum deciduum (Erythroxylaceae) em ovinos. Pesquisa Veterinária Brasileira, v. 24, n. 3, p. 165-168, 2004.

23. Mosmann, T. Rapid colorimetric assay for cellular growth and survival: application to proliferation and cytotoxicity assays. J Immunol Methods. v. 65, n. 1-2, p. 55-63, 1983

\section{Adriana G. Pereira', Antônio Carlos S. Menezes ${ }^{1 *}$, Mirley L. dos Santos', Tamires S. Vieira ${ }^{1}$, Renato G. Santos ${ }^{1} \&$ Elisângela P. S. Lacerda ${ }^{2}$}

${ }^{1}$ Ciências Exatas e Tecnológicas. Universidade Estadual de Goiás. Caixa Postal 459, CEP 750001-970, Anápolis, GO, Brasil.

${ }^{2}$ Instituto de Ciências Biológicas. Universidade Federal de Goiás. Campus Samambaia, Caixa Postal 131, CEP 74001-970, Goiânia, GO, Brasil.

*E-mail: antonio.menezes@ueg.br 